\title{
The Effects of Contraceptive Pills on Oral Health: A Review Study
}

\author{
Maha T Al-Saffar* \\ Assistant Professor, Department of Dental Basic Science, College of Dentistry, Mosul University, Iraq \\ *Corresponding Author: Maha T Al-Saffar, Assistant Professor, Department of Dental Basic Science, College of Dentistry, Mosul \\ University, Iraq.
}

Received: October 21, 2019; Published: November 13, 2019

DOI: $10.31080 /$ ASDS.2019.03.0700

\begin{abstract}
Oral pills for contraception are a harmless and successful methods of preventing pregnancy used by women in the world. These drugs were first used around 1960s with different dose of progesterone and estrogen were recorded to produce unnecessary adverse effects like localized osteitis, gingival inflammation, gingival melanosis, changes in salivary components, alterations in salivary flow rate orally. This review article brief the special effects of contraceptive pills on oral health specially by including many English written reports to evaluate these unwonted effects on oral cavity and its possible mechanism of action in producing these effects.
\end{abstract}

Keywords: Oral Contraceptives; Gingivitis; Oral Health; Adverse Effects; Estrogen; Progesterone

\section{Introduction}

Contraceptives pills have been used as a method of contraception for a long period of time, and large number of women have used them over the last 60 years [1]. Combined form of Oral Contraceptive (COC) is consist of progestogen and oestrogen [2].

The contraceptive pills act mainly by affecting the ovulation by troubling the role of oestrogen and progestin. progestin acts mainly by decrease the liberation of Luteinizing Hormone which release from the pituitary gland anterior lobe. In addition it acts by slows the sperm transport by creating a thick cervical mucus, so, prevent capacitation "activation of enzymes that allow the sperm to break through the ovum". Estrogen decrease the discharge of LH and Follicle Stimulating Hormone this result in the prevention of ovulation. So it proposed that estrogen change the uterus secretion produced oedematous patches with thick cellularity, so implantation is less possible to occur. at the present time contraceptives pills which used in the obstacle of pregnancy, treatment of endometriosis an menstrual disturbances [3].
Mechanism of oral contraceptive effects on oral health

The contraceptive progesterone and estrogen effects on the periodontium and oral mucosal surface have been investigated widely.

The estrogen effects on the periodontal tissue are summarized as follows

- Decreases keratinization and increasing Glycogen in the epithelium that results in decrease the epithelial barrier effectiveness [5].

- Increases in the connective tissue component of acid mucopolysaccharide in oral tissue [5].

- $\quad$ Decrease inflammation mediated by T-cell [6].

- $\quad$ Enhance the construction of gingival fibroblasts $[7,8]$.

- Stimulates the production and maturation of connective tissue in the gingiva [7].

- Increases the quantity of inflammation in gingival with no plaque accumulation [9].

- $\quad$ Enhance production of cells in blood vessels $[10,11]$. 
- Decrease production of leukocyte from the bone marrow [12].

- $\quad$ Stimulates phagocytosis action of PMNL [13].

The progesterone effects on periodontal tissue are summarized as follows:

- $\quad$ Enhance the prostaglandins production $[7,14]$.

- Increases the production of prostaglandin E2 and Polymorphonuclear leukocytes the gingival crevicular fluid $[7,14,15]$.

- Decrease the anti-inflammatory effects of glucocorticoid [16].

- Inhibits PDL fibroblast from synthesis of collagen [17].

- Inhibits proliferation of gingival fibroblast [18].

- Change the prototype and rate of collagen manufacture in gingival which may result in declining maintenance and repair activity [19].

- Increases vascular dilatation, so increasing the permeability and gingival fluid volume and GCF $[7,11]$.

Clinical studies investigate that the higher incidence of gingival enlargement, gingival inflammation and loss of attachment in woman taking contraceptive pills [19,20]. Gingival inflammation appears to be associated to high content of sex hormones present in COC [21]. It is also noteworthy that gingival inflammation are reliant on the time of use of COC [19].

The using of oral contraceptives will increases amount sex hormones in female in attendance in the environment of subgingival tissue which may direct to disease of periodontium. It also demonstrated that females taking contraceptives pills could have larger affinity for bleeding from gingiva, greater periodontal pocket depth and loss of attachment because of enlarged vascularity and enlarge the amount of crevicular fluid gingivally, with augment in Privately species and approximately 16 times increase in Bacteroides species level than standard flora of gingival [22].

Other oral side effects of contraceptive pills

Kalkwarf K L (1978) in his study showed that in group presently intriguing contraceptives pills had a elevated index of gingival Inflammation and a lesser index of Oral Debris compared with control group [23].

Tilakaratne A (2000) clarified that the use of contraceptive pills consisting of progesterone and oestrogen could produce changes of hormones similar to pregnancy changes, related with augmented occurrence of gingivitis. Also there is a significant advanced loss of attachment with extended uses of contraceptives pills when compared with control group [24].

Mullally BH., et al. (2007) showed that patients taking contraceptives pills may have more sever gingival bleeding, more severe periodontal attachment loss, higher plaque levels, and deeper periodontal pocketing, than those who were not taking the pill [25].

Vijay G (2010) demonstrated that contraceptive pills when used for long duration may guide to bad oral hygiene state and increased vulnerability to inflammation of periodontal tissue [26].

Brusca MI., et al. (2010) showed that the use of contraceptive pills may increase the danger of severe periodontitis and may enhance the growth of special species of Candida in periodontal pockets. The females use contraceptive pills demonstrate a higher percentage of P. intermedia, P. Gingivalis, and A. actinomycetemcomitans when compared to control group [27].

Arumugam M., et al. (2015) clarified that Candida. albicans the most frequent species remote from the user and the non user patients, then " Candida dubliniensis, Candida krusei, Candida tropicalis, Candida glabrata and Candida parapsilois"[28].

Zakaryia A., and Smadi L., (2019). Showed that the use of contraceptive pills can affect the periodontium resulting in gingival diseases especially by using of newer generation [1].

A quantifiable differences also been demonstrated in the salivary content of patients having contraceptive pills, including a reduce in the protein concentration, hexosamine fucose, sialic acid, total electrolytes and hydrogen; in few studies, salivary flow changes also seen [29].

Females taking contraceptives pills had 16-times elevated amount of species of Bacteroides and showed a double to 3-times increase in the frequency of localized osteitis after third mandibular molars extraction [30].

Several research have demonstrated "a hyperplastic oedematous gingivitis" after taking contraceptives pills, which eliminated after pills are stopped [31].

In high dose, contraceptives pills produce a hypertrophic gingivitis, bleeding and pregnancy type epulis, marked gingival 
erythema and. in therapeutic which may produce gingivitis with an enlarge in gingival exudate and enhance the amount of inflammation in papillae [32].

Fluid in gingival crevice is appeared as a very sensitive pointer of inflammation of gingiva. only some studies have demonstrated increased in the rate of flow fluid in patients taking contraceptive pills [10]. but with no difference significantly of flow rate was appeared in controls and female taking contraceptives pills [33]. On the other hand, constant mouth dryness was observed in $30 \%$ of women taking these pills [33].

Gingival melanosis is also seen in women using contraceptive pills. Oestrogen produce discharge of increasing the amount of cortisol binding globulin that cause decrease in the level of free cortisol in blood with increase the secretion of $\beta$-melanocyte stimulating hormone and ACTH. The first one may produce pigmentation of mucosa of oral cavity [34].

\section{Conclusion}

Several research and clinical studies obtainable in the past and now a day have concluded that oral contraceptive pills have certain effects on oral health. The judgment of dependent dose special effects led to the improvement of new production of oral contraceptive pills with minimum dose content in current years [35], although a small number of studies have been done to explore their special effects on oral health, the evidence powerfully provide evidence that they will not preteens health risks. So, women taking contraceptive pills have a low danger for having periodontal and gingival disease [36,37].

\section{Bibliography}

1. Smadi L and Zakaryia A. "The Association between the Use of New Oral Contraceptive Pills and Periodontal Health: A Matched Case-Control Study". Journal of International Oral Health 10.3 (2018): 127-131.

2. Mouton A. "Non-contraceptive effects and uses of hormonal contraception". South African Family Practice 49.7 (2007): 3233.

3. Abd-Ali EH and Shaker NT. "The effect of oral contraceptive on the oral health with the evaluation of Salivary IgA and Streptococcus mutans in some Iraqi women". Marietta Daily Journal 10.1 (2013): 52-63.
4. Nandini DB., et al. "Oral contraceptives and oral health: an insight”. International Journal of Medical and Dental Sciences 5.2 (2016): 1297-1303.

5. Manson JD. "The aetiology of chronic periodontal disease". In: Eley B, Manson JD, editors. Periodontics. London: Kimpton Medical Publications (2004): 38-61.

6. Josefsson E., et al. "Anti-inflammatory properties of estrogen. I. In vivo suppression of leukocyte production in bone marrow and redistribution of peripheral blood neutrophils". Cellular Immunology 142 (1992): 67-78.

7. Miyagi M., et al. "Effects of sex hormones on production of prostaglandin E2 by human peripheral monocytes". Journal of Periodontology 64 (1993): 1075-1078.

8. Beagrie GS. "Observation on cell biology of gingival tissue of mice”. British Dental Journal 121 (1966): 417-420.

9. Reinhardt RA., et al. "Influence of estrogen and osteopenia/osteoporosis on clinical periodontitis in postmenopausal women". Journal of Periodontology 70 (1999): 823-828.

10. Lindhe J and Branemark P. "Changes in microcirculation after local application of sex hormones". Journal of Periodontal Research 2 (1967): 185-193.

11. Lindhe J and Branemark P. "Changes in vascular permeability after local application of sex hormones". Journal of Periodontal Research 2 (1967): 259-265.

12. Cheleuitte D., et al. "In vitro secretion of cytokines by human bone marrow: effects of age and estrogen status". The Journal of Clinical Endocrinology and Metabolism 83 (1998): 20432051.

13. Hofmann R., et al. "Activity of phagocytic granulocytes in patients with prostatic cancer". Urological Research 14.6 (1986): 327-330.

14. ElAttar TM. "Prostaglandin E2 in human gingiva in health and disease and its stimulation by female sex steroids". Prostaglandins 11 (1976): 331-341.

15. Ferris GM. "Alteration in female sex hormones: their effect on oral tissues and dental treatment". Compendium 14 (1993): 1558-1570. 
16. Chen TL., et al. "Glucocorticoid receptors and inhibition of bone cell growth in primary culture". Endocrinology 100 (1977): 619-628.

17. Tilakaratne A and Soory M. "Androgen metabolism in response to oestradiol- 17beta and progesterone in human gingival fibroblasts (HGF) in culture". Journal of Clinical Periodontology 26 (1999): 723-731.

18. Mealey BL and Moritz AJ. "Hormonal influences: effects of diabetes mellitus and endogenous female sex steroid hormones on the periodontium". Periodontol 200032 (2003): 59-81.

19. Thomson ME and Pack ARC. "Effects of extended systemic and topical folate supplementation on gingivitis in pregnancy". Journal of Clinical Periodontology 9 (1982): 275-280.

20. Sooriyamoorthy $M$ and Gower DB. "Hormonal influences on gingival tissue: relationship to periodontal disease". Journal of Clinical Periodontology 16 (1989): 201-208.

21. Pankhurst CL., et al. "The influence of oral contraceptive therapy on the periodontium - duration of drug therapy". Journal of Periodontology 52 (1981): 617-620.

22. Ali I., et al. "Oral Health and Oral Contraceptive - Is it a Shadow behind Broad Day Light? A Systematic Review". Journal of Clinical and Diagnostic Research 10.11 (2016): ZE01-ZE06.

23. Kalkwarf KL. "Effect of oral contraceptive therapy on gingival inflammation in humans". Journal of Periodontology 49.11 (1978): 560-563.

24. Tilakaratne A., et al. "Effects of hormonal contraceptives on the periodontium, in a population of rural Sri Lankan women". Journal of Clinical Periodontology 27.10 (2000):753-757.

25. Mullally BH., et al. "Current oral contraceptive status and periodontitis in young adults". Journal of Periodontology 78.6 (2007):1031-1036.

26. Vijay G. "Relationship of duration of oral contraceptive therapy on human periodontium-A clinical, radiological and biochemical study". Indian Journal of Dental Research 2.2 (2010): 168174.

27. Brusca MI., et al. "The impact of oral contraceptives on women's periodontal health and the subgingival occurrence of aggressive periodontopathogens and Candida species". Journal of Periodontology 81.7 (2010): 1010-1018.
28. Arumugam M., et al. "A comparative evaluation of subgingival occurrence of Candida species in periodontal pockets of female patients using hormonal contraceptives and non-usersA clinical and microbiological study". Oral Health and Dental Management 14.4 (2015): 206-211.

29. Jensen J., et al. "The effect of female sex hormones on subgingival plaque”. Journal of Periodontology 52 (1981): 599-602.

30. Sweet JB and Butler DP. "Increased incidence of postoperative localized osteitis in mandibular third molar surgery associated with patients using oral contraceptives". American Journal of Obstetrics and Gynecology 127 (1977): 518-519.

31. Chevallier ME. "Mouth manifestations and oral contraceptives". Rev Odontol Stomatol 28 (1970): 96.

32. Lindhe J and Bjorn AL. "Influence of hormonal contraceptives on the gingival of women". Journal of Periodontal Research 2 (1967): 1-6.

33. Preshaw PM., et al. "Experimental gingivitis in women using contraceptives". Journal of Dental Research 80 (2001): 20112015.

34. El-Ashiry GM., et al. "Effects of oral contraceptives on the gingiva”. Journal of Periodontology 42 (1971): 273-275.

35. Abdollahi M and Radfar A. "A review of drug induced oral reactions". The Journal of Contemporary Dental Practice 4.1 (2003): 10-31.

36. Kemmeren JM., et al. "Third generation oral contraceptives and risk of venous thrombosis: A metanalysis". British Medical Journal 323 (2001): 131-134.

37. Domingues RS and Rahal Ferraz B. "Influence of combined oral contraceptives on the periodontal condition". Journal of Applied Oral Science 20.2 (2012): 253-259.

\section{Volume 3 Issue 12 December 2019 (C) All rights are reserved by Maha T Al-Saffar.}

